\title{
Inclusão de alunos com implante coclear: a visão dos professores
}

\author{
Juliana Pêgas Costa* \\ Celeste Azulay Kelman** \\ Adriana Ramos Silva Góes***
}

\section{Resumo}

Este artigo aborda a educação dos alunos surdos submetidos à cirurgia de implante coclear, matriculados em escolas públicas do Município do Rio de Janeiro. Os recentes avanços tecnológicos têm contribuído para o surgimento de uma nova especificidade a ser considerada no contexto da inclusão escolar. A orientação linguística para o aluno com implante coclear envolve a promoção da língua falada, ao contrário dos demais estudantes surdos que, obedecendo ao Decreto 5.626/05, tem a inclusão da língua brasileira de sinais - Libras como sua primeira língua (L1) e o português, na modalidade escrita, como sua segunda língua (L2). Embora também possa usar a Libras e, portanto, precisar de intérprete, este necessita de adaptaçóes bastante diferenciadas. Os dados foram coletados a partir de entrevistas semiestruturadas com doze professores de diferentes escolas. A partir dos resultados, observa-se que, além da ausência do sistema de Frequência Modular Pessoal (FM) nestas escolas, ainda há desconhecimento por parte dos profissionais em relação às consequências de um implante e adequaçóes a serem realizadas no processo de ensino, o que prejudica de maneira significativa o cotidiano escolar deste grupo. Resultados nos mostram que alguns dos alunos implantados também frequentam a sala de recursos, aprendendo a língua de sinais. Alguns deles, inclusive, têm a preferência pelo uso dessa língua.

Palavras-chave: Implante coclear; Educação inclusiva; Prática pedagógica.

\footnotetext{
* Mestranda em Educaçáo da Universidade Federal do Rio de Janeiro. Rio de Janeiro, Rio de Janeiro, Brasil.

** Professora doutora da Universidade Federal do Rio de Janeiro. Rio de Janeiro, Rio de Janeiro, Brasil.

*** Professora da Universidade Federal do Rio de Janeiro. Rio de Janeiro, Rio de Janeiro, Brasil.
} 


\section{Inclusion of students with cochlear implants: overview of teachers}

\section{Abstract}

This study refers to the education of deaf students who have been through cochlear implants' surgery and are registered in public schools of the city of Rio de Janeiro. Recent technological advances have contributed to some new features in the field of school inclusion. Linguistic orientations for a student with cochlear implant involves spoken language. On the contrary, other deaf students, obeying to Decree 5.626/05, receive instruction in Brazilian Sign Language, as it is considered their first language (L1) and Portuguese, in written mode, as their second language (L2). Although they can also use Sign language and therefore need an interpreter, the students with cochlear implant need differentiated adaptations. Data were collected through semi structured interviews with seven teachers of different public elementary schools. Results show that besides the absence of FM equipment in those schools, there is still an unawareness from some teachers and other professionals of the consequences of cochlear implants, their specificities and the adaptations that are needed along learning process, which makes their day-by-day activities worse. Results also show that some of these implanted students often attend the resource room, therefore learning sign language. Some of them even prefer using sign language than speaking.

Keywords: Cochlear implant; Inclusion education; Pedagogical practice.

\section{Introdução}

Nos últimos anos, os estudos a respeito de implante coclear (IC) vêm avançando e, com eles, diversas discussôes a respeito de suas implicaçôes sócio educacionais. O implante consiste em uma cirurgia em que eletrodos são implantados na cóclea com a intenção de estimular o nervo auditivo por meio de impulsos elétricos. É importante ressaltar que tal procedimento, apesar de eficaz para resolver a maioria dos casos de deficiência auditiva, em nosso entender, não deve ser visto como um processo de cura da surdez, principalmente porque estáo envolvidos outros fatores como, por exemplo, a identidade e a cultura surda. De acordo com Wrigley:

[...] surdos são pessoas que ouvem com ouvidos defeituosos. Se pudéssemos consertar os ouvidos, eles estariam ouvindo. Esta lógica comum na verdade é comum, mas não necessariamente lógica. Os negros são pessoas brancas que possuem pele escura. Se pudéssemos consertar a pele, eles seriam brancos, as mulheres são homens com genitália errada...; e por aí vai. Essas transposições cruas revelam um tecido social de práticas pelas quais nós sabemos quais identidades são tanto disponíveis quanto aceitáveis. (WRIGLEY, 1996, p. 71). 
Nesse sentido, é necessário pensar a respeito da metodologia utilizada para a educação de alunos surdos implantados, uma vez que muitas escolas têm utilizado a língua portuguesa sem pensar em adaptaçōes, e ignorando a língua de sinais. Negligenciam, consequentemente, a cultura e seus aspectos identitários. Vale lembrar que, apesar de já ser uma realidade no país, a maioria das escolas ainda enfrenta grandes barreiras quanto à inclusáo por diversos fatores, dentre os quais a falta de uma metodologia específica que atenda às diferenças e especificidades em sala de aula. A inclusão do aluno surdo é um desafio ainda maior a ser enfrentado, já que não estamos falando simplesmente de "deficientes auditivos", mas de pessoas que possuem uma língua formal na modalidade viso-espacial. Além disso, há uma enorme dificuldade em incluir o surdo em contextos pensados e estabelecidos por e para ouvintes. A respeito da inclusão, Skliar (2006, p. 28) disse que“[...] o sistema que exercia o seu poder excluindo tem se tornado agora cego àquilo que acontece lá fora - e já não pode controlar com tanta eficácia, se propóe a fazê-lo por meio da inclusão ou, para melhor dizer, mediante a ficção da promessa integradora”.

Muitos anos depois, e também os avanços tecnológicos, nos levam a pensar a situação da inclusão de alunos com implante coclear. Estudos com crianças implantadas (QUEIROZ e KELMAN, 2007; KELMAN e QUEIROZ, 2008) apontam para a falta de preparo do professor em sala de aula, ausência de uma metodologia adequada e da língua de sinais no desenvolvimento da escrita e de todo o processo ensino-aprendizagem. Além disso, reforçam a importância do respeito pela língua, cultura e identidade surda. Portanto, é de enorme importância ressaltar que o implante coclear e a língua de sinais não se excluem mutuamente, mas ao contrário, o implante torna-se mais uma opçáo para que o surdo seja bilíngue e possa utilizar a língua portuguesa e a de sinais conforme sua necessidade, podendo ainda servir como intérprete aos seus pares surdos. Como afirma Kelman:

O bilinguismo em crianças com implante coclear deve ser estimulado, pois a pessoa que sabe mais de uma língua está melhor preparada para a vida. Um surdo que fale e sinalize pode transitar em mais espaços e contextos socioculturais do que aquele que é usuário exclusivo de língua de sinais. (KELMAN, 2010, p. 37).

Neste processo bilíngue, o aluno com implante coclear também deve ter garantido o direito de receber o sistema de Frequência Modulada Pessoal (FM), pois este sistema auxilia na compreensão da fala, tendo em vista que as ondas de rádio garantem um volume satisfatório e diminuem, significativamente, a entrada sonora de ruídos que interferem na compreensão do que está sendo falado.

O sistema FM auxiliará na comunicação entre o aluno com implante e o professor, na medida em que estimula o desenvolvimento da compreensão da fala oral. É importante compreendermos que, além do respeito à sua identidade e língua, o surdo implantado também precisará ser respeitado em seu processo de aprendizado dos significados dos sons, um "mundo" anteriormente desconhecido por ele, sendo fundamental um acompanhamento fonoaudiológico e, em alguns casos, também psicológico, de modo a auxiliar sua construção e associação mental das palavras ex- 
pressadas por meio das línguas orais, até que este atinja a plena compreensão da fala. Contudo, não se deve impedir que este aluno também tenha acesso à língua de sinais, principalmente se esta foi a sua primeira língua adquirida, ainda antes do implante.

Na Austrália, Hyde e Punch (2011) conduziram um estudo em que entrevistaram 247 pais e 151 professoras de alunos implantados. Tinham como objetivo investigar os modos de comunicação que as crianças utilizavam e o papel da língua de sinais em suas vidas. Nesse estudo, a idade média das crianças implantadas era de 10 anos, e a idade média em que haviam sido submetidas à cirurgia era de 4 anos. As crianças continuavam usando a língua de sinais e, tanto pais quanto professores, achavam que os benefícios do bilinguismo se concentravam em três áreas: contribuir para o desenvolvimento da compreensão da língua oralizada, oferecer uma maneira das crianças continuarem a se comunicar, ainda que sem a parte externa do implante (ou sem a bateria), e contribuir para a participaçáo social e desenvolvimento da formaçáo de identidade surda nessas crianças.

Como seria a percepção dos professores da rede pública municipal do Rio de Janeiro? Teriam eles interesse em reforçar os conteúdos apenas na forma oral da língua portuguesa ou estimulariam, junto à família, que a criança mantivesse, no caso de já ter adquirido, a língua de sinais?

\section{Método}

Essa pesquisa é um recorte de uma pesquisa maior coordenada pela segunda autora, onde foram entrevistados pais, professores, alunos implantados e seus colegas. Aqui serão considerados os dados referentes às respostas dos professores entrevistados.

A metodologia utilizada foi de caráter qualitativo, em uma perspectiva sociocultural construtivista. Valsiner (2000, p. 50) define cultura como um todo integrado no qual as "interconexôes sistêmicas entre as motivaçôes fisiológicas e suas transformaçóes através das instituiçóes sociais estâo no núcleo do conceito". Para Bruner (2001), a mente jamais pode ser considerada como natural. Ela é sempre cultural, embora Vygotsky (1991) considere que a cultura seja historicamente e socialmente construída. Nesse sentido, a construção sociocultural da mente do aluno com IC passa pela maneira como o professor da sua classe e da sala de recursos lidam com essa nova situação.

Foram realizadas entrevistas semiestruturadas com doze educadores da rede municipal do Rio de Janeiro, entre eles, dez regentes e dois da sala de recursos multifuncionais. Esses professores atuam na educação infantil e no ensino fundamental, de primeiro e segundo ciclo.

As entrevistas foram realizadas pelos auxiliares de pesquisa (alunos de Graduação, de Pós-Graduação e professores colaboradores). Nas entrevistas, procurou-se obter informaçóes a respeito do desenvolvimento e aprendizado do aluno com IC, sua atenção e interesse pelos conteúdos, a interaçáo entre o aluno e os colegas de classe, dentre outros aspectos. As entrevistas foram gravadas e transcritas para a análise dos dados. Essa pesquisa foi aprovada pelo Comitê de Ética em Pesquisa da Secre- 
taria Municipal de Saúde e Defesa Civil, sob n. 297 A/2012. Todos os participantes assinaram um Termo de Consentimento Livre e Esclarecido - TCLE, autorizando a divulgação dos resultados para fins acadêmicos e científicos.

A fim de preservar a identidade dos professores, os participantes dessa pesquisa receberão as siglas (P1), (P2)..., para os dez professores regentes e, os professores da sala de recursos serão denominados de (PSR1) e (PSR2). Entre os doze educadores entrevistados, onze sáo do sexo feminino e um do sexo masculino. $\mathrm{O}$ tempo que lecionam varia de dois a vinte anos. A maioria deles possui somente um aluno implantado em sala.

\section{Resultados}

A análise dos dados nos propicia refletir sobre diversas questóes de enorme relevância para se compreender o processo ensino-aprendizagem do aluno com implante coclear. Para apresentação dos resultados, dividimos os dados em quatro subcategorias: 1 - Rendimento do aluno com IC; 2 - Interaçáo social entre aluno implantado e colegas de turma; 3 - Frequência à sala de recursos; e 4 - Formaçáo dos professores.

\section{Rendimento do aluno com IC}

A maioria dos professores afirma que os alunos implantados apresentam bom rendimento nas aulas, apesar de demonstrarem um visível atraso quanto aos demais alunos. No entanto, ao serem perguntados sobre a dificuldade que eles possuem em entender o que se dizem, todos afirmam que apresentam muita dificuldade. Podemos observar na fala de (P1):

Dentro das suas possibilidades, é muito boa. Ela é muito esperta, está sempre atenta, surpreende a gente. Mas, quando comparada à turma, tem um pouco de atraso [...]. O conteúdo programático ela tem dificuldade de compreender, mas o que não se relaciona com a aula, ela entende.

A fala do professor mostra que a aluna, apesar de ser implantada, ainda apresenta dificuldades em compreender o que é falado e, consequentemente, não entende o conteúdo programático. Esta e as demais respostas dos professores ajudam a reforçar a ideia de que o implante coclear não é e não pode ser visto como a cura da surdez, e que, após o implante, ele irá escutar perfeitamente. $\mathrm{O}$ resultado do implante coclear irá variar de acordo com diversos fatores, entre os quais a idade em que foi feita a cirurgia, o tempo que o aluno utiliza o IC, a aceitação da criança e da família, a manutenção e acompanhamento do uso. O que queremos reforçar aqui é que é necessário que o aluno implantado não seja visto como ouvinte pelos professores, mas que eles estejam atentos às necessidades educacionais desse aluno em sala de aula.

Outro aspecto muito importante a ser observado é a falta de uso do sistema FM por parte dos professores que possuem aluno com IC em sua sala de aula. Por intermédio de um microfone sem fio, usado próximo ao professor, o sinal é encaminhado direto para o implante coclear do aluno. A Portaria n. 1.274, de 25 de junho 
de 2013, passa a oferecer FM para estudantes de cinco a dezessete anos que utilizam aparelhos auditivos e/ou implante coclear. Mas, aparentemente, esse direito de receber gratuitamente o sistema via SUS tem sido largamente ignorado, talvez por ser tâo recente.

Infelizmente, percebemos que há falta de uma tecnologia assistiva que garanta o acesso à informaçáo de maneira nítida, além da falta de preparo por parte de muitos professores e de uma metodologia que atenda as reais necessidades dos alunos. Podemos observar isso na fala do (P2):

Eu falo diretamente com a turma e não me prendo diretamente ao aluno implantado [...]. Quando eu falo com a turma ele náo se prende, mas eu acho que é falta de atenção mesmo.

O mesmo professor, ao ser perguntado se o aluno entende o que ele diz, responde:

Não, somente com a ajuda do intérprete e através de "mímica". A Libras, no momento, é que faz ele entender o que está ocorrendo no mundo ao redor.

Podemos observar que o professor atribui o desinteresse do aluno implantado ao que ele diz ser falta de atenção. Porém, vemos, na fala seguinte, que não se trata simplesmente de falta de atenção, já que o aluno se comunica por meio da Libras. Nota-se que é através da língua de sinais que este aluno constrói seu entendimento sobre o mundo e que é nessa língua que ele se reconhece e compreende os conteúdos da escola. Quanto à dificuldade encontrada pelo aluno em entender o que é dito, (P3) relata:

\footnotetext{
Tem que chegar bem perto e falar bem perto; a certa distância ela não entende. Ela olha, lê, lê os lábios. O ruído atrapalha. Ela tá tentando conseguir um mais moderno, pois o barulho dificulta. [...] Eu não sei muito como lidar com isso. Sem ajuda de um intérprete de Libras é complicado.
}

É válido destacar que nenhum dos alunos implantados observados possui o aparelho FM, o que, aparentemente, tem dificultado ainda mais a compreensão do conteúdo ensinado em sala de aula por parte desses alunos. A fala de (P3) deixa claro que nessa turma não há o uso de Libras ou do sistema FM, e que o aluno precisa ficar fazendo leitura labial. O professor relata também que não há intérprete em sua sala, dificultando ainda mais o aprendizado.

Diversos fatores podem influenciar no baixo rendimento escolar do aluno implantado, como o número de alunos em sala, o posicionamento do aluno na sala de aula, entre outros. A fala de (P7) ilustra tais situaçóes:

O rendimento escolar do aluno é baixo. Somente em matemática ele consegue se sair um pouco melhor, também porque a mãe dele está pagando uma explicadora de matemática, assim é bem 
mais fácil, pois a explicadora atende só a ele. Ela consegue dar uma atenção individualizada, pode falar de frente pra ele o tempo todo, articulando com calma, tirando as dúvidas, mas para interpretar e escrever ele tem muita dificuldade.

A fala do professor demonstra que o aluno apresenta baixo rendimento nas disciplinas, exceto em matemática, pois, segundo o professor, recebe reforço escolar particular.

Os dados mostram que para compreender o que é dito, o aluno precisa estar próximo ao professor para fazer leitura labial, ou, em alguns casos, que o professor fale próximo ao implante para facilitar a transmissão do som. É possível notar, por meio das entrevistas com os professores, que o aluno implantado enfrenta enorme dificuldade nas salas de aula inclusivas que não utilizam a Libras para o processo de ensino aprendizagemou que não tem o sistema FM.

Algumas respostas evidenciam essas importantes questóes. A resposta de (P4) nos apresenta um caso em que o aluno chega a desligar seu aparelho, evidenciando ou a rejeição ao método oralista, ou o incômodo com os ruídos sem significado:

Como ele sabe fazer leitura labial eu sou atento a isso, às vezes ele desliga o aparelho. Isso ocorria mais antes do que hoje.

Quando questionado se os alunos com IC entendem perfeitamente o que é falado na sala de recursos e quais são as dificuldade de um aluno com IC para entender, (PSR1) responde:

Não totalmente, pois há necessidade que se diminua os ruídos e que a professora se posicione de frente para a aluna e fale pausadamente. [...] O que atrapalha é o barulho da própria turma e ruídos exteriores.

Apesar disso, (PSR1) relaciona um maior desenvolvimento dos seus alunos,em relação aos demais surdos, à colocação do IC, inclusive no domínio da língua de sinais:

Tenho observado o desenvolvimento maior nos alunos com implante coclear, tanto na aquisição do domínio da Libras, como em Língua Portuguesa. Percebo que a aluna tem adquirido conceitos com maior facilidade e o domínio dos mesmos quando comparada a alunos surdos não implantados.

É possível perceber que, na maioria das escolas, a língua oral auditiva prevalece, ainda que sem o apoio do sistema FM, enquanto que a língua de sinais é desvalorizada e deixada de lado muitas vezes, sendo usada quase que exclusivamente na sala de recursos. $\mathrm{Na}$ medida em que o aluno cresce, se ele encontra uma escola onde há outros adolescentes surdos, ele tende a buscar um vínculo identitário com a surdez. Afinal, ele ainda é surdo. 


\section{Interação social entre aluno implantado e colegas de turma}

Os professores relatam que não há casos de preconceito entre os alunos. Entre aluno implantado e outros alunos surdos, os professores apontam que se comunicam em língua de sinais. No entanto, analisando as entrevistas, nota-se que em alguns momentos, principalmente fora da sala, o aluno não fica entrosado com a turma. Podemos observar isso na fala de (P3), ao ser perguntado se há casos de preconceito entre seu aluno implantado e os colegas:

Não há preconceito, ao contrário, eles têm carinho por ele. Há um bom entrosamento. No recreio em brincadeiras coletivas ele vai pro futebol, quando ele é escolhido pro time. Nos últimos três meses ele tem interagido melhor com o grupo. Na hora do lanche ele fica sozinho, eu tenho que levar ele pra ficar com o grupo.

É possível observar, por meio da fala do professor, que apesar de náo relatar casos de preconceito, o aluno fica sozinho na hora do recreio. Isso pode ocorrer por diversos fatores, inclusive por causa de um sentimento de náo pertencimento a esse grupo ouvinte por parte do aluno surdo implantado. Sendo perceptível um discurso ambíguo do professor ao afirmar um bom entrosamento entre a turma.

Todo o corpo escolar deve ser envolvido nas questóes que se relacionam à inclusão de alunos com quaisquer especificidades. No caso de um aluno com IC, os demais docentes também precisam ser orientados em relação à necessidade de se direcionar com clareza ao aluno, ou ainda de utilizar a língua de sinais, caso esta seja do conhecimento de ambos.

Quanto ao relacionamento entre aluno surdo e aluno implantado, os professores relatam que há um excelente entrosamento e nenhum preconceito, já que o aluno implantado também se comunica em Libras. É o que aponta (P10): "Não tem diferencial, porque ele se comunica em Libras".

\section{Frequência à sala de recursos}

A sala de recursos multifuncionais é um espaço para o atendimento educacional especializado que auxilia o processo de inclusão dos alunos com necessidades educacionais especiais em classes comuns. O Programa foi criado pela Portaria Interministerial 13/2007 (BRASIL, 2010 a), no sentido de atender a "[...] necessidade histórica da educação brasileira, de promover as condiçóes de acesso, participação e aprendizagem dos alunos público-alvo da educaçáo especial no ensino regular, possibilitando a oferta do atendimento educacional especializado, de forma não substitutiva à escolarização" (p. 3).

O aluno surdo também frequenta a sala de recursos em sua escola, se nela houver, ou em outra instituição. Os dados da pesquisa também mostraram que os alunos que frequentam esse programa demonstram melhor desempenho nas atividades escolares. A maioria dos alunos pesquisados frequenta a sala de recursos, como podemos observar. Ao ser indagado, diz (P6): 
Sim. Ela frequenta na própria escola com a professora que sabe Libras e ainda uma instrutora surda. Na turma tenho uma estagiária do curso de Pedagogia para me auxiliar em relação à aluna.

Porém, alguns alunos não frequentam a sala de recursos, principalmente porque a família rejeita e não aceita a surdez do filho. No dizer de (P7):

Eu já falei com a escola e com a mãe que ele precisa participar de uma sala de recursos, mesmo que seja em outra escola, mas a máe acha que ele não precisa. Eu já falei pra ela também que era bom pra ele aprender a Libras e ter contato com outras crianças surdas, mas a mãe não aceita que o filho é surdo.

A participação da família é um fator de enorme importância no desenvolvimento do aluno surdo, mas infelizmente muitas famílias negam a surdez do filho, não permitindo seu acesso à língua de sinais ou até mesmo à sala de recursos. A fala de (P9) demonstra como a participação da família é essencial nesse processo:

A menina não vai melhor porque a família não chega junto como deveria. Ela faltou uma semana direto e ninguém deu explicação porque que faltou. Entáo isso prejudica um pouco a evolução. Mas é muito boa. [...] A menina tem outro problema, a família não quer que ela use a língua de sinais.

A aluna a que (P9) se refere também não frequenta a sala de recursos. De acordo com ele, apesar de ter bom rendimento, falta uma parceria com a família.

Um dos alunos pesquisados com bom rendimento escolar faz uso com frequência da sala de recursos e da língua de sinais, como podemos verificar na fala de (P8):

Ela frequenta a sala de recursos na própria escola com a professora que sabe Libras e ainda uma instrutora surda. Na turma tenho uma estagiária do curso de Pedagogia para me auxiliar em relação à aluna.

Observa-se, portanto, que a frequência à sala de recursos é um dos fatores que influencia no rendimento escolar dos alunos implantados. Porém, muitos deles não fazem uso desse recurso em sua escola, não recebem acompanhamento de um fonoaudiólogo, não têm acesso ao sistema FM e não utilizam a língua de sinais. Esses fatores, entre outros, podem comprometer seu desenvolvimento e sua aprendizagem.

\section{Formação dos professores}

Nota-se, por meio das falas dos professores entrevistados, a falta de preparo para lidar com as especificidades encontradas dentro de sala. Quanto ao surdo, o problema vai mais além, já que há, em alguns casos, uma diferença linguística entre professor ouvinte, que domina a língua oral auditiva e o aluno surdo, que domina a língua de sinais. A maior queixa dos professores entrevistados foi exatamente a ausência de uma formação que atenda às necessidades do aluno com variados graus de surdez e que fazem uso de diferentes modalidades comunicativas. A maioria deles 
não tem conhecimento da língua de sinais e não sabe como lidar e se comunicar com esses alunos. Isso fica claro nas palavras da (P3):

Eu não sei muito como lidar com isso. Sem ajuda de Libras é complicado. [...] Deveria ter uma base melhor pra poder dar aula. A gente se vira da maneira que pode e que não pode.

As entrevistas com os professores mostram até certa angústia por não terem sido preparados para dar aula para alunos com amplo espectro de surdez e modalidades comunicativas, como podemos observar na fala de (P7):

Eu também não recebi nenhum preparo para ensinar um aluno surdo. Eu fico preocupada porque eu quero ajudar ele, vou pra casa pensando como, mas eu não sei o que fazer!

Ao perguntarmos a (P8) se gostaria de dizer algo mais sobre seu aluno implantado, novamente foi possível perceber a urgência da formação de professores:

Sim, mas não é sobre a aluna, e sim sobre a falta de uma formação específica nesta área. Isto ainda precisa ser desenvolvido de maneira geral no Município.

Entre os dez professores regentes, somente um (P9) relatou ter conhecimento em língua de sinais. Segundo ele, conhecer a Libras favorece o processo ensino-aprendizagem:

Eu sei Libras, passo minha aula toda assim: falo para os alunos ouvintes e ao mesmo tempo em Libras para os alunos não ouvintes. E com esse método percebi que os alunos ouvintes estão aprendendo Libras também.

Portanto, vimos que a inclusão já é realidade no país e que é necessário que a escola se modifique para atender às necessidades educacionais especiais comunicativas desse novo alunado surdo que começa a aparecer nas escolas. É muito importante que se abra um diálogo entre esses profissionais que atuam em classes inclusivas com o governo e há uma urgência em programas de formação continuada que abordem o tema da educação de alunos surdos implantados.

\section{Discussão}

As novas tecnologias assistivas vêm avançando e tornam-se aliadas a muitos casos de deficiência. O implante coclear tem sido responsável por uma significativa melhora em muitos casos de deficiência auditiva. No entanto, é preciso frisar que ele não representa a cura da surdez, principalmente porque não podemos deixar de atentar para fatores como o tempo de desenvolvimento cognitivo para aquisição de uma nova língua com base no som, bem como a questấo de identidade e cultura surdas que permanecem presentes.

A partir das falas dos professores entrevistados, foi possível observar diversas situaçóes muito importantes para pensarmos no contexto sócioeducacional dos alu- 
nos surdos com implante coclear. Vimos que alguns desses alunos apresentam baixo rendimento escolar e certa dificuldade em se relacionar com os seus colegas ouvintes, principalmente pela dificuldade na comunicação entre eles.

Esses resultados nos mostram que, apesar de inclusivas e com o atendimento educacional especializado, muitas escolas ainda não estão capacitadas, por diversos fatores, entre os quais, destacamos a falta de preparo dos profissionais e a carência de uma formação continuada para esses professores que têm em sua classe alunos surdos e/ou implantados. Concordamos com Quadros e Massutti (2007, p. 242) ao afirmarem que: "o processo educacional sempre privilegiou o uso da língua portuguesa, conferindo um status aos seus falantes, política essa que continua a trazer consequências negativas para a vida dos surdos".

Vimos que a maioria das escolas pesquisadas utiliza somente a língua portuguesa no processo ensino-aprendizagem, o que influencia diretamente no rendimento dos alunos surdos. Vale ressaltar que é muito importante que o aluno implantado adquira a Libras. É importante que o surdo seja bilíngue e possa utilizar as duas línguas conforme sua necessidade comunicativa e social.

Foi possível observar, por meio dos resultados, que apresentaram melhor rendimento acadêmico os alunos que falam, usam Libras e frequentam a sala de recursos. Ou seja, obtiverem melhor desempenho os alunos que se constituem como usuários das duas línguas, por terem mais ferramentas simbólicas para a formação dos conceitos científicos que a escola oferece. Acreditamos que, sob esta nova perspectiva bilíngue para surdos implantados, os resultados podem ser ainda melhores quando for usado o sistema FM, uma vez que o aparelho utiliza um microfone sem fio que transmite o sinal de fala para um minúsculo receptor, o que proporciona uma melhor clareza na recepção do som.

Outro aspecto que nos chamou atenção é a dificuldade que os professores encontram em desenvolver seu trabalho com alunos surdos em sala de aula. Eles se queixam que não foram formados nem preparados para lidar com a surdez, já que não possuem conhecimento em língua de sinais e desconhecem seus aspectos culturais. Quanto a isso, alguns estudos, como por exemplo os de Nóvoa (1995), apontam para o fato de que é possível estabelecer relação entre o conhecimento que o professor traz de sua formação com a realidade da inclusão. Segundo esse autor, a escola pode ser o local para aperfeiçoar a prática pedagógica e favorecer o aprendizado do aluno. Porém, não podemos deixar de refletir sobre o papel do governo e das políticas públicas para a formação de professores nesse processo.

\section{Conclusões}

O implante coclear é um recurso que auxilia de maneira significativa na reabilitação de casos de deficiência auditiva. Porém, junto com os avanços tecnológicos na área da surdez, é necessário que haja muita discussão e reflexão a respeito de suas implicaçóes médica, social e, sobretudo, pedagógica. O que reforçamos aqui é a necessidade de se pensar como se dá o ensino desses alunos implantados matriculados na rede municipal de ensino, que trabalham na perspectiva inclusiva e contam com o auxílio das salas de recursos multifuncionais. 
Vimos que muitas escolas demonstraram não estarem preparadas para receber alunos com surdez, devido à falta do sistema FM, de uma metodologia que atenda suas necessidades e, principalmente, à falta de preparo desses profissionais que não tiveram formação adequada para receber o aluno surdo, com ou sem implante coclear.

Portanto, é necessário que a escola atenda às necessidades educacionais especiais comunicativas do aluno surdo implantado. É fundamental que haja diálogo entre os professores que atuam em classes inclusivas com pesquisadores educacionais e na área da saúde auditiva e, também, com gestores educacionais em âmbito do governo federal, estadual e municipal, já que é visível a urgência de programas de formação continuada que abordem o tema da educação de alunos surdos com implante coclear.

\section{Referências}

BRASIL. Manual de orientaçáo: programa de implantaçâo de salas de recursos multifuncionais. Brasília: MEC/SEESP, 2010 a.

BRASIL. Decreto n. 5.626, de 22 de dezembro de 2005. Regulamenta a Lei n. 10.436, de 24 de abril de 2002, que dispóe sobre a Língua Brasileira de Sinais - Libras, e o art. 18 da Lei n. 10.098, de 19 de dezembro de 2000. Diário Oficial da União, Brasília, DF, 23 dez. 2005, Seção 1, n. 246, p. 28-30. Disponível em: <http://www. planalto.gov.br/ccivil_03/_Ato2004-2006/2005/Decreto/D5626.htm>. Acesso em: 27 abr. 2013.

BRASIL. Portaria n. 1.274, de 25 de junho de 2013. Inclui o Procedimento de Sistema de Frequência Modulada Pessoal (FM) na Tabela de Procedimentos, Medicamentos, Órteses, Próteses e Materiais Especiais (OPM) do Sistema Único de Saúde. Brasília: Ministério da Saúde. Disponível em: <http://brasilsus.com.br/legislacoes/ gm/119537-1274.html >. Acesso em: 28 abr. 2013.

BRUNER, J. A cultura da educaçáo. Porto Alegre: Artmed, 2001.

HYDE, M.; PUNCH, R.The modes of communication used by children with cochlear implants and role of sign in their lives. American Annals of the Deaf, 155 (5), 535-549, 2011.

KELMAN, C. A. Dilemas sobre o implante coclear: implicações linguísticas e pedagógicas. Revista Espaço: Informativo técnico-científico do INES, n. 33, jan./jun. 2010, p. 33-41.

KELMAN, C. A.; QUEIROZ, E. F. Signs of resilience in writing acquisition of a child with cochlear implant.Comunicação apresentada no 2nd International Conference on Special Education. Marmaris, Turkey, jun. 2008.

NÓVOA, A. Os professores e sua formaçáo. Lisboa: CODEX, 1995.

QUADROS, R. M.; MASSUTTI, M. Codas brasileiros: libras e português em zonas de contato.In: QUADROS, R.; PERLIN, G. (Org.). Estudos surdos II. Rio de Janeiro: Arara Azul, 2007.

QUEIROZ, E. F.; KELMAN, C. A. Implicações do implante coclear no processo de aquisição da escrita de uma criança surda. In: TANAKA, E. D. O.; MARQUEZINE, M. C.; BUSTO, R. M.; FUJISAWA, D. S. \& MANZINI, E. J. (Orgs.). As necessidades educacionais especiais: altas habilidades, transtornos globais do desenvolvimento e deficiências. Londrina: EdUEL, 2009.

SKLIAR, C. A inclusão que é "nossa” e a diferença que é do "outro". In: RODRIGUES, D. (Org.). Inclusão e educaçáo: doze olhares sobre a educação inclusiva. São Paulo: Summus, 2006.

VALSINER, J. Culture and human development. London: Sage Publications, 2000.

VYGOTSKY, L. S. A formaçáo social da mente. São Paulo: Martins Fontes, 1991.

WRIGLEY, O. The politics of deafness. Washington: Gallaudet University Press, 1996. 


\section{Correspondência}

Juliana Pêgas Costa - Rua 43, lote 22, Quadra 95, Loteamento soter- sobrado. Bairro Itaipu. Niterói, CEP: 24342-655. Rio de Janeiro - Rio de Janeiro, Brasil.

E-mail: jujupegas@hotmail.com - celeste@kelman.com.br - adrianaramos.ufrj@gmail.com

Recebido em 10 de julho de 2014

Aprovado em 21 de outubro de 2014 